\title{
Structural basis of diabetic nephropathy in microalbuminuric NIDDM patients: a light microscopy study
}

\author{
T. B ertani ${ }^{1,2}$, V.G ambara ${ }^{1,2}$, G.R emuzzi $i^{1,2}$ \\ ${ }^{1} \mathrm{M}$ ario N egri I nstitute for Pharmacological R esearch, B ergamo, I taly \\ ${ }^{2} \mathrm{D}$ ivision of Nephrology and D ialysis, O spedali R iuniti di B ergamo, B ergamo, I taly
}

Summary The objective of the study was to evaluate early structural changes occurring in patients with non-insulin-dependent diabetes mellitus (NIDDM) and microalbuminuria by light microscopy. Basal renal biopsy was performed in patients who were subsequently randomized to different antihypertensive treatments. Fourteen NIDDM patients aged 36-65 years (duration of diabetes $9 \pm 7$ years) with microalbuminuria (mean urinary albumin excretion $66 \pm 49 \mu \mathrm{g} / \mathrm{min}$ ) underwent percutaneous renal biopsy. Control biopsies were obtained from five patients of similar age undergoing nephrectomy for renal neoplasia with normal renal function and no history of renal disease. Control and diabetic biopsies were processed by light microscopy and stained with haematoxylin and eosin, periodic acid Schiff, M asson's trichrome and silver methenamine. The percentage of globally sclerotic glomeruli was evaluated. Glomerular volume was determined using perimeter analysis. A semiquantitative assessment (range 0 to $3+$ ) was made of mesangial sclerosis, interstitial fibrosis, tubular atrophy, arteriosclerosis and arteriolar hyalinosis. G lomerular volume was significantly increased in diabetic as compared to control glomeruli ( $3.2 \pm 8$ vs $1.8 \pm 7, p<0.01$ ). M esangial sclerosis ( 0.9 vs $0, p<0.0001)$ and arteriolar hyalinosis ( 0.91 vs $0.2, p<0.022)$ were significantly higher in diabetic compared to control subjects. No significant differences between diabetic and control subjects were found in the percentage of globally sclerotic glomeruli or in the extent of interstitial fibrosis, tubular atrophy and arteriosclerosis. Thus NIDDM patients with microalbuminuria show histological findings consistent with diabetic nephropathy characterized by glomerular hypertrophy, mesangial sclerosis and arteriolar hyalinosis. However, the renal histological changes are mild and appear less marked than in insulin-dependent diabetic patients. [D iabetologia (1996) 39: 1625-1628].

Keywords Glomerulosclerosis, diabetes mellitus, $\mathrm{M} \mathrm{i-}$ croalbuminuria, glomerular volume and light microscopy.
D iffuse and nodular glomerulosclerosis are typical lesions of most insulin-dependent (IDD M ) and non-insulin-dependent (NIDDM) diabetic patients with clinical proteinuria and renal function impairment $[1,2]$. M orphometric studies in the last 20 years have established that the sclerotic process results from an excessive production of mesangial matrix leading to

Corresponding author: D r. T. B ertani, M ario N egri I nstitute for Pharmacological R esearch, Via G avazzeni 11, 24125 B ergamo, I taly

A bbreviations: IDDM, Insulin-dependent diabetes mellitus; NIDD M, non-insulin-dependent diabetes mellitus reduction of the glomerular capillary surface and progressive decline of renal function [3-4].

While glomerular lesions in diabetic patients with clinical proteinuria have been well-documented, the nature of renal lesions in those patients who only have microalbuminuria is still elusive.

The few studies available, all in ID D M, found that patients with low levels of microalbuminuria have a heterogeneous pattern of abnormalities ranging from no signs of glomerular damage to glomerulosclerosis [5-7]. Conversely, ID D M patients with higher levels of microalbuminuria most often had diabetic glomerulosclerosis. A t present no data are available 
Table 1. Clinical characteristics of patients at renal biopsy

\begin{tabular}{|c|c|c|c|c|c|c|c|c|}
\hline $\begin{array}{l}\text { A ge } \\
\text { (years) }\end{array}$ & $\begin{array}{l}\text { Sex } \\
\text { (female/male) }\end{array}$ & $\begin{array}{l}\text { D iabetes dura- } \\
\text { tion (years) }\end{array}$ & $\begin{array}{l}\text { Glucose } \\
(\mathrm{mmol} / \mathrm{l})\end{array}$ & $\mathrm{HbA}_{1 \mathrm{c}}(\%)$ & $\begin{array}{l}\text { Serum creati- } \\
\text { nine }(\mu \mathrm{mol} / \mathrm{l})\end{array}$ & $\begin{array}{l}\text { UAE } \\
(\mu \mathrm{g} / \mathrm{min})\end{array}$ & $\begin{array}{l}\text { MAP } \\
(\mathrm{mmHg})\end{array}$ & $\begin{array}{l}\text { R etinopathy } \\
\text { (yes/no) }\end{array}$ \\
\hline $53 \pm 8$ & $6 / 8$ & $9 \pm 7$ & $9.5 \pm 2.8$ & $6.9 \pm 1.2$ & $0.886 \pm 0.088$ & $66 \pm 49$ & $116 \pm 6$ & $7 / 7$ \\
\hline
\end{tabular}

D ata are mean \pm SD. UA E; urinary albumin excretion; M A P; mean arterial pressure

by light or electron microscopy of renal lesions in NID D M patients with microalbuminuria. The aim of the present study is to evaluate the early structural changes occurring in patients with NIDDM and microalbuminuria through the use of light microscopy.

\section{Subjects and methods}

We selected 14 patients with mild hypertension (90$104 \mathrm{mmH} g$ diastolic pressure), microalbuminuria (urinary albumin excretion $20-200 \mu \mathrm{g} / \mathrm{min}$ ) and serum creatinine under $0.896 \pm 0.08 \mu \mathrm{mol} / \mathrm{l}$ for the study. The group consisted of $6 \mathrm{fe}-$ males and 8 males with ages ranging between 36 and 65 years and diabetes duration from 1 to 25 years. Table 1 summarizes clinical and laboratory data. A II patients underwent percutaneous renal biopsy using a conventional technique. Five surgical biopsies obtained from patients of similar age (55.03 \pm 7.51 years) undergoing unilateral nephrectomy for kidney neoplasia and with no previous history of renal diseases were used for comparison. A fter the removal of the kidney, small fragments of tissue, which excluded the most superficial glomeruli, were cut and immediately fixed.

A II kidney biopsies were fixed in Dubosq-Brazil solution and routinely processed for paraffin embedding. Serial sections of $3 \mu \mathrm{m}$ thickness were cut and stained with haematoxylin and eosin, Masson's trichome, silver methenamine and periodic acid-Schiff reagent. A t least eight glomeruli were examined for each biopsy.

In each patient the number and the percentage of globally sclerotic glomeruli were determined. A semiquantitative assessment of renal damage was performed. The following histological findings were considered: mesangial sclerosis, interstitial fibrosis, tubular atrophy, arteriosclerosis, and arteriolar hyalinosis.

M esangial sclerosis was graded from 0 to $3+(0=$ no changes, $1+=$ mild changes consisting in an expansion of mesangial matrix or cells without reduction of capillary lumina, $2+=$ moderate changes consisting in an expansion of mesangial matrix or cells with reduction of capillary lumina, $3+=$ severe changes consisting in an expansion of mesangial matrix or cells with marked reduction or occlusion of capillary lumina.

Interstitial fibrosis and tubular atrophy were graded from 0 to $3+(0=$ no changes, $1+=$ changes affecting less than $25 \%$ of the biopsy specimen, $2+=$ changes affecting 25 to $50 \%$ of the biopsy specimen, $3+=$ changes affecting more than $50 \%$ of the biopsy specimen).

A rteriosclerotic changes which consisted of fibrous thickening of the intima often associated with duplication of the lamina elastica, leading to reduction of the vascular lumen, were graded from 0 to $3+(0=$ no changes, $1+=$ mild changes, $2+=$ moderate changes, $3+=$ severe changes).

A Ithough arteriolar hyalinosis can be observed in arteriosclerosis, it is also frequently detected in diabetes and is considered part of diabetic nephropathy. Therefore, arteriolar hyalinosis, consisting of periodic acid Schiff positive material permeating the arteriolar wall and leading to the narrowing or occlusion of vascular lumen, was evaluated with a score ranging from 0 to $3+(0=$ no changes $1+=$ mild changes $2+$ $=$ moderate changes $3+=$ severe changes $)$.

Glomerular volume $\left(V_{G}\right)$ was determined as previously described [8]. Briefly, images of all glomeruli from each biopsy in two sections more than $180 \mu \mathrm{m}$ apart were digitized from the light microscope using a videocamera (Panasonic, $M$ atsushita Electrical Co., O saka, Japan) and stored in the computer memory (M acintosh IIfx; A pple Computer Inc., Cupertino, Calif., U SA ). G lomerular cross sections were displaced on the computer screen at a final enlargement of $\times 1000$ and the area of the capillary tuft outlines was measured using area perimeter analyses (I mage v 1.55; N ational Institutes of $\mathrm{H}$ ealth, Bethesda, M.D., U SA). The mean number of analysed glomerular sections was 20 (range 8-30). The mean glomerular tuft cross-sectional area $\left(A_{m}\right)$, including area of capillary space, was computed for each biopsy and $V_{G}$ calculated using the equation:

$\mathrm{V}_{\mathrm{G}}=\frac{\beta}{\mathrm{k}}\left(\mathrm{A}_{\mathrm{m}}\right)^{3 / 2}$ $\left[\mu \mathrm{m}^{3}\right]$

where $k=1.1$ is a size distribution coefficient, and $\beta=1.38$ is the shape coefficient of glomeruli [9].

\section{Statistical analysis}

A II results are expressed as mean \pm standard deviation. Student's t-test was used to compare glomerular volume and percentage of sclerotic glomeruli.

Chi-square or Fisher's exact tests were used for comparison of scores of histological change.

\section{Results}

M ean glomerular volume was significantly increased in diabetic patients as compared to control subjects (3.2 \pm 8 vs $1.8 \pm 7 \mu \mathrm{m}^{3} \mathrm{p}<0.01$ ) (Fig. 1). B y light microscopy the spectrum of pathological changes was evenly distributed in all patients. G lomeruli were moderately enlarged with a mild diffuse increase of mesangial matrix and few areas of segmental sclerosis (Fig. 2). The increase of mesangial matrix was not associated with mesangial or endocapillary hypercellularity.

The glomerular capillary wall was not markedly thickened. The percentage of globally sclerotic glomeruli in diabetic patients was $6.6 \%$, not significantly different from that observed in control subjects $(2.6 \% p=N S)$. No significant glomerular changes were detected in control biopsies (Fig. 3). 


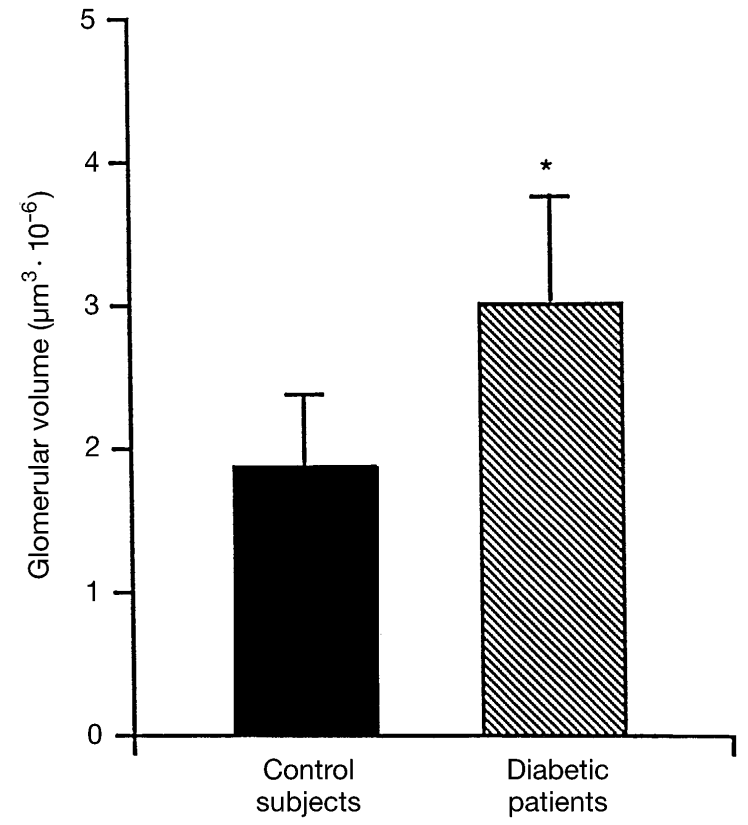

Fig. 1. Distribution of glomerular volume in control subjects and in NIDDM patients * $p>0.01$

In diabetic specimens there was a focal mild interstitial fibrosis and tubular atrophy; however, the score of tubulointerstitial changes was not significantly different from control subjects.

A rteriolar hyalinosis was observed in almost all patients and was significantly higher than in control subjects $(p<0.022)$.

A rteriosclerotic changes were similarly represented in diabetic and control patients. The spectrum and the extent of renal damage are summarized in Table 2 .

\section{Discussion}

O ur study through the use of light microscopy, demonstrates results for patients with NIDDM, microalbuminuria and mild hypertension consistent with a diagnosis of diabetic nephropathy with glomerular hypertrophy, mesangial sclerosis and arteriolar hyalinosis.

While all patients had a remarkable increase in glomerular volume, glomerulosclerosis and arteriolar hyalinosis were mild. Renal lesions also included some chronic tubulointerstitial lesions and arteriosclerosis which, however, were also seen in control subjects and could be regarded as non-specific, agerelated changes. The few available data on light microscopy findings in NIDDM microalbuminuric diabetic patients have mostly been published in abstract form $[10,11]$. Some showed lesions of diffuse or nodular glomerulosclerosis that we have been unable to confirm in the present study $[10,11]$.

O ur light microscopy findings of mild glomerular lesions are at variance with those observed in ID D M

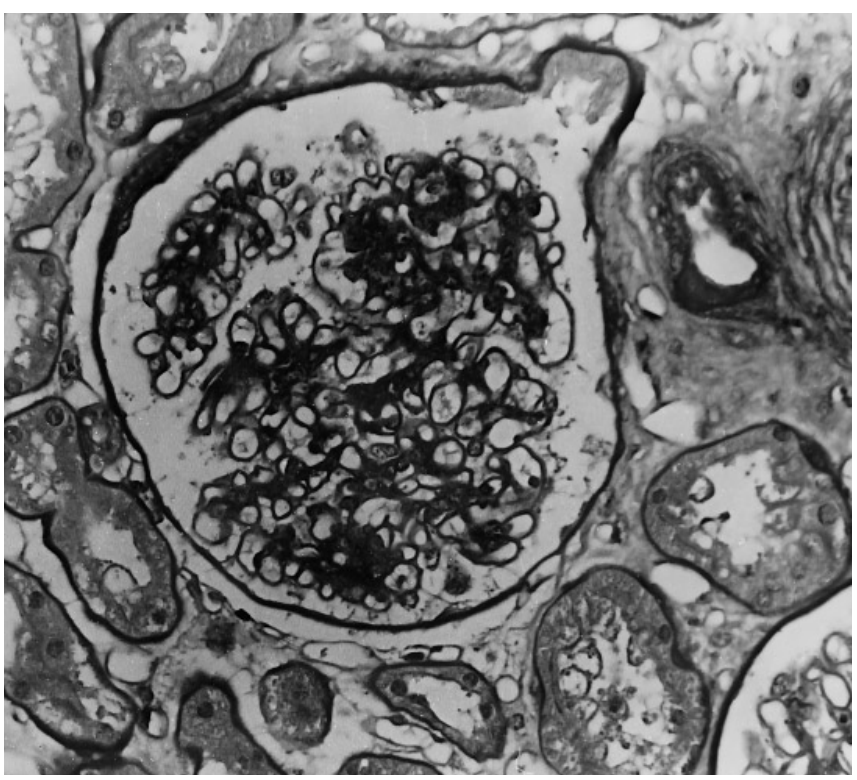

Fig. 2. G lomerulus from a patient with NID D M and microalbuminuria showing diffuse mesangial sclerosis. $\mathrm{H}$ yalin changes are present in an arteriole (PA S × 250)

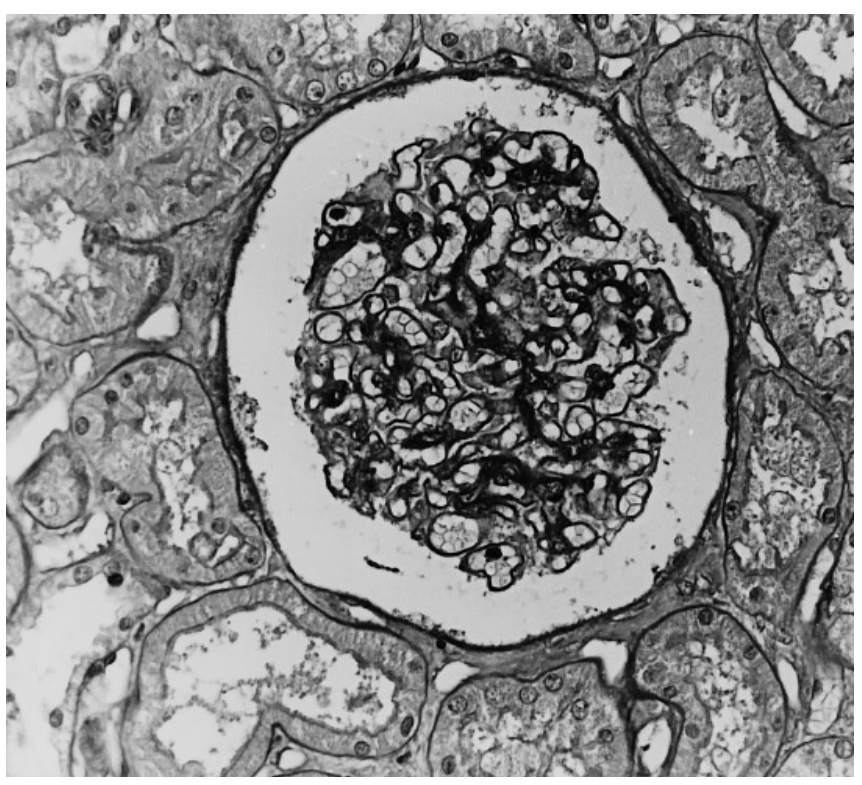

Fig. 3. Glomerulus from a control patient showing no significant changes (PA S $\times 400$ )

patients with similar levels of microalbuminuria, in whom more marked glomerular structural changes have been detected [5-7].

H owever, pathological findings here are in agreement with a preliminary study performed in 69 NIDDM patients with microalbuminuria by Fioretto and co-workers [12] who demonstrated that in these patients glomerular changes were less pronounced than in IDDM.

The reasons why glomerular structure might be more protected in NIDD M require further studies. 
Table 2. Semiquantitative assessment of pathological changes

\begin{tabular}{|c|c|c|c|c|c|c|c|c|}
\hline & $\mathrm{n}$ & $\begin{array}{l}\text { Glom. } \\
\text { volume }\end{array}$ & $\begin{array}{l}\text { G lobally } \\
\text { sclerotic glom }\end{array}$ & $\begin{array}{l}\text { M esangial } \\
\text { sclerosis }\end{array}$ & $\begin{array}{l}\text { Interstit. } \\
\text { Fibr. }\end{array}$ & $\begin{array}{l}\text { Tub. } \\
\text { atrophy }\end{array}$ & A rteriosc. & A rt. hyal. \\
\hline $\begin{array}{l}\text { Control } \\
\text { subjects }\end{array}$ & 5 & $1.8 \pm 7$ & 2.6 & 0 & 1 & 1 & 0.8 & 0.2 \\
\hline $\begin{array}{l}\text { Diabetic } \\
\text { patients }\end{array}$ & 14 & $3.2 \pm 8^{b}$ & 6.6 & $0.9^{c}$ & 1.1 & 1.06 & 0.4 & $0.91^{a}$ \\
\hline
\end{tabular}

${ }^{a} p<0.022 ;{ }^{b} p<0.01 ;{ }^{c} p<0.0001$ vs control subjects

$D$ ata are expressed as mean score (range 0 to $3+$ )

\section{References}

1. G ambara V, M ecca G, R emuzzi G, B ertani T (1993) H eterogeneous nature of renal lesions in type II diabetes. JA SN : 3: $1458-1466$

2. Ritz E, Keller CK, B ergis K H, Siebels M (1994) R enal involvement in type II diabetes. Curr Opin Nephrol Hyperten 3: 137-144

3. E llis E N, Steffes M W, G oetz FC, Sutherland D ER, M auer SM (1986) G lomerular filtration surface in type I diabetes mellitus. Kidney Int 29: 889-894

4. M auer SM, Steffes M W, E llis E N, Sutherland DE R, B rown EM (1984) Structural-functional relationship of diabetic nephropathy. J Clin Invest 74: 1143-1155

5. Chavers B M , B ilous RW, E Ilis E N, Steffes M W, M auer SM (1989) U rinary albumin excretion as a predictor of renal structure in typel diabetic patients without overt proteinuria. N E ngl J M ed 320: 966-970

6. Walter JD, Close CF, Jones SL et al. (1992) G lomerular structure in type 1 (insulin-dependent) diabetic patients with normo- and microalbuminuria. Kidney Int 41: 741-748
G Iom., G lomerular; Fibr., fibrosis; Tub., tubular; A rteriosc., arteriosclerosis; A rt. hyal., arteriolar hyalinosis

7. Fioretto P, Steffes M W, M auer M (1994) G lomerular structure in nonproteinuric IDDM patients with various levels of albuminuria. D iabetes 43: 1358-1364

8. I ordache B E , I mberti O, Foglieni C, R emuzzi G, B ertani T, R emuzzi A (1994) E ffects of angiotension converting enzyme inhibition on glomerular capillary wall ultrastructure in M W F/Ztm rats. JA SN 5: 1378-1384

9. Weibel ER (1979) Practical methods for biological morphometry. In: E.R.Weibel (ed) Stereological methods. Vol. 1. A cademic Press, London: pp 1-45

10. Pinel N, Fadel B, Bilous RW, Corticelli P, Halimi S, Cordonnier DJ (1995) R enal biopsies in 30 micro- and macroalbuminuric non-insulin dependent (type 2) (NIDDM) patients: heterogeneity of renal lesions. International Society of N ephrology. Proceedings, p. 195 (A bstract)

11. Shoji T, A kagaki Y, H ayashi T et al. (1995) D isagreement between glomerular lesions and clinical course in the early phase of NIDDM. International Society of Nephrology Proceedings, p. 194 (A bstract)

12. Fioretto $P, M$ auer $M, B$ rocco $E$ et al. (1996) Patterns of renal injury in N ID D M patients with microalbuminuria. Diabetologia 39: S31-S38 